\title{
Avaliação da Qualidade do Leite na Bacia Leiteira de Pelotas, RS. Efeito dos Meses do Ano
}

\author{
Helenice de Lima Gonzalez¹, Vivian Fischer², Maria Edi Rocha Ribeiro³, Jorge Fainé Gomes ${ }^{3}$, \\ Waldyr Stumpf Jr. ${ }^{3}$, Marcelo Abreu da Silva ${ }^{4}$
}

\begin{abstract}
RESUMO - Os efeitos dos meses do ano sobre a composição e produção do leite foram avaliados através do acompanhamento de 10 unidades produtoras de leite, divididas em três sistemas de produção classificados como especializado (ES), semi-especializado (SE) e não-especializado (NE), durante 11 meses do ano. Foram coletadas amostras de leite diretamente dos tanques refrigeradores para determinação das características físico-químicas e contagem de células somáticas (CCS). Quantificaram-se a incidência de mastite e a produção média de leite (litros/vaca/dia) e coletaram-se amostras de água utilizada para consumo e limpeza, de pastagem, concentrado e silagem. O delineamento adotado foi o completamente casualizado, em arranjo fatorial desbalanceado, considerando como fatores os meses do ano, os sistemas de produção e a sua interação. Não foi encontrada variação significativa entre os meses estudados para produção de leite, valores de crioscopia, porcentagens de gordura, extrato seco, nitrogênio não-protéico, CCS, composição química, contagem de coliformes da água e composição bromatológica do concentrado. Os maiores valores de proteína verdadeira do leite foram observados em outubro e novembro, enquanto os maiores de caseína, em outubro, novembro, março e abril. O extrato seco desengordurado foi superior em dezembro e a acidez variou juntamente com a incidência de mastite, sendo superior nos meses de novembro e maio. Em relação à proteína bruta, ocorreu interação entre meses e sistemas. Foram observadas correlações negativas entre produção de leite e gordura, mastite e CCS, e correlação positiva entre produção de leite e lactose. O leite produzido nos diversos meses do ano diferiu, principalmente, quanto à incidência de mastite, fração protéica, extrato seco desengordurado e acidez. A qualidade da água não se modificou expressivamente nos meses em que foi amostrada e se apresentou dentro dos limites considerados aceitáveis.
\end{abstract}

Palavras-chave: característica físico-química do leite, contagem de células somáticas, mastite, produção de leite, variação sazonal

\section{Evaluation of Milk Quality on Different Months of Year at Pelotas Dairy Basin, RS}

ABSTRACT - The effect of months of year upon milk production and quality was estimated through evaluation of ten dairy production units classified as specialized (S), partially specialized (PS) and not specialized (NS), which were visited on 11 months of the year. Bulk tank milk was sampled to determinate physical and chemical characteristics and somatic cell count (SCC), mastitis percentage and milk production (liters/cow/day). Besides that, samples of feeds and water used for drinking and cleaning were collected. There were not significant differences between months for milk production, crioscopy, percentages of fat, total solids, non protein nitrogen and SCC, but true protein percentages were higher on October and November, and casein showed higher values on October, November, March and April. Total solids were higher on December. Acidity varied in same way as mastitis percentage, higher on November and May. Negative relations between milk production and percentage of fat, percent of mastitis and somatic cell count were detected, while a positive one was verified between milk production and lactose percentage. Milk obtained during the year showed differences between months for protein fraction, acidity, solids non fat and percentage of mastitis. Water quality did not change among collection months and it was acceptable for drinking and cleaning.

Key Words: mastitis, milk physical-chemical characteristics, milk production, sazonal variation, somatic cells count

\section{Introdução}

A região sul do Brasil, em especial o Rio Grande do Sul, apresenta grande diversidade edafoclimática e condições propícias para o desenvolvimento da pecuária leiteira com animais de raças especializadas como Holandês e Jersey. Observam-se, no entanto, acentuadas variações de temperatura do ar e do solo entre os períodos de inverno e de verão, com conseqüentes variações sazonais nas taxas de

\footnotetext{
${ }^{1}$ Médico Veterinário, Mestre em Zootecnia - helenice@ufpel.tche.br - Rua Professor Araújo, 1943 - Pelotas - RS - $96020-360$.

2 Professor Adjunto do Departamento de Zootecnia, Faculdade de Agronomia - UFPEL - Pelotas - RS - bolsista CNPq.

3 Pesquisador do EETB - EMBRAPA - Pelotas - RS.

4 Professor do Departamento de Agrometeorologia e Plantas Forrageiras - UFRGS - Porto Alegre - RS.
} 
crescimento das forrageiras (Stumpf et al., 2000). O produtor de leite desenvolve sua atividade em áreas predominantemente não superiores a 20 hectares e tem, como maior fator de estrangulamento da produção, a falta de reserva alimentar (volume e qualidade) nos meses de março, abril e novembro de cada ano (Bitencourt et al., 2000).

A globalização de mercados, em função da grande e variada oferta de produtos lácteos importados, induziu o consumidor brasileiro a tornar-se mais exigente em relação à qualidade dos produtos oferecidos. A indústria laticinista, por sua vez, tem se modernizado e exigido do produtor um leite de melhor qualidade, na tentativa de tornar-se mais competitiva. Dentro desse contexto, nos próximos anos, serão implementadas normas nacionais de padrões de qualidade de leite, determinadas pelo Programa Nacional de Melhoria da Qualidade de Leite, do Ministério da Agricultura (Ribeiro et al., 2000) e pela Normativa 51 já em vigor (Brasil, 2002).

Apesar de não estarem relacionados com a qualidade intrínseca do leite, o volume e a sazonalidade de produção são critérios bastante considerados para o pagamento do produto. Interessa aos laticínios captar leite junto aos produtores que forneçam grandes volumes diários de leite e que apresentem pequena variação sazonal da produção. Isso representa uma diluição nos custos operacionais e de transporte, além de uma melhor logística para recolhimento do produto. A pequena variação sazonal proporciona um melhor planejamento por parte da indústria e a minimização da ociosidade do parque industrial em determinadas épocas do ano (Fonseca, 2001).

Objetivou-se, com o presente trabalho, estudar as variações sazonais da produção e características físico-químicas do leite na bacia leiteira de Pelotas, RS, ao longo de onze meses do ano.

\section{Material e Métodos}

O experimento foi conduzido em 10 unidades de produção (UPL) pertencentes à bacia leiteira de Pelotas, localizadas nos seguintes municípios: São Lourenço do Sul (1), Canguçu (1), Cerrito (1), Capão do Leão (2), Santa Vitória do Palmar (1), Arroio Grande (1) e Pelotas (3), representando diferentes sistemas de produção adotados na região, desde aquelas que praticam a atividade de forma extensiva até aquelas que aplicam intensivamente os recursos tecnológicos disponíveis. As UPL foram classificadas em três sistemas de produção: especializado, semiespecializado e não-especializado, considerando-se quantidade e disponibilidade de volumoso e concentrado fornecidos, o grau de utilização de tecnologia, o número de vacas, o recebimento de assistência técnica, o tipo de ordenha, as condições higiênicas de manipulação do leite e a média de produção (L/vaca/dia).

A coleta de dados foi realizada mensalmente nas dez UPL durante 11 meses, de 01/09/1999 a $31 / 08 / 2000$. As UPL foram divididas em três sistemas, conforme o somatório de pontos obtidos por um sistema de pontuação realizado de acordo com as características de produção e tecnologia adotadas. As UPL do sistema especializado ficaram com pontuação de 1 a 0,6 ; do semi-especializado, de 0,5 a 0,3 ; e do não-especializado, com pontuações inferiores.

O sistema especializado foi constituído de quatro UPL, uma destas composta de um rebanho da raça Jersey e as demais da raça Holandesa. As UPL neste sistema apresentam sala de ordenha tipo espinha de peixe, com circuito fechado, sala de espera pavimentada e sistema de limpeza dos equipamentos automatizado. Utilizaram-se medidas de controle de mastite como caneca de fundo preto, "pré-dipping", secagem dos tetos com papel toalha descartável, "pós-dipping", descarte de animais portadores de mastite crônica e tratamento com antimicrobianos de liberação lenta na secagem das vacas. Estas propriedades utilizaram alimentação composta por silagem, pasto cultivado de forma intensiva e concentrado balanceado, em quantidades variadas ao longo do ano. A água foi acessível a todos os animais.

O sistema semi-especializado foi constituído de quatro UPL, das quais duas possuem rebanhos da raça Jersey e as demais, rebanhos da raça Holandesa. Apenas duas UPL possuem sala de ordenha tipo espinha de peixe, em circuito fechado; as demais utilizam o sistema de ordenha balde ao pé, conforme Normativa 51 (Brasil, 2002). Não foram adotadas todas as medidas de controle de mastite recomendadas. A alimentação era composta de concentrado balanceado com quantidades variáveis, silagem e pasto cultivado, mas sem manter qualidade e constância no fornecimento durante o ano.

O sistema não-especializado foi constituído de duas UPL - uma com rebanho da raça Jersey e outra com animais mestiços. Uma propriedade possuía sistema de ordenha balde ao pé e a outra, ordenha manual Normativa 51 (Brasil, 2002). Na maior parte

R. Bras. Zootec., v.33, n.6, p.1531-1543, 2004 
do tempo, não foram adotadas medidas de controle de mastite ou, tais práticas foram implementadas de maneira inadequada durante o estudo. Não foram fornecidas ração balanceada, silagem ou pastagem cultivada, apresentando condições nutricionais e sanitárias precárias. Água nem sempre foi acessível os animais.

As amostras de leite in natura foram obtidas dos tanques refrigeradores de expansão ou de imersão após a ordenha da tarde. Realizou-se a homogenização por, aproximadamente, dois minutos, retirando-se uma amostra de $350 \mathrm{~mL}$ de leite, colocada em frascos de vidro. Concomitantemente, foi coletada uma amostra de $35 \mathrm{~mL}$ de leite em frasco apropriado, contendo dicromato de potássio, para posterior contagem de células somáticas. As amostras foram acondicionadas em caixas isotérmicas contendo gelo.

Durante a ordenha, foram realizados os testes da caneca de fundo preto, para detecção de quartos com mastite clínica, e o California Mastitis Test (CMT), segundo Schalm \& Noorlander (1957), para detecção dos quartos com mastite subclínica. Os resultados dos quartos reagentes foram utilizados para o cálculo da incidência de mastite do rebanho, que foi calculada dividindo-se o número de quartos reagentes (ao teste da caneca de fundo preto e/ou ao CMT) pelo número total de quartos avaliado; o resultado foi multiplicado por 100 .

A avaliação das características fisico-químicas do leite foi feita pela determinação da densidade do leite, por meio de termolactodensímetro de Quevenne (Tronco, 1997), e da acidez, segundo o método de Dornic (Fagundes , 1997) - o resultado foi expresso em ${ }^{\circ} \mathrm{D}$. O teor de gordura foi medido por intermédio do butirômetro de Gerber, segundo Fagundes (1997); o extrato seco total (EST), pelo método de Ackermann (Tronco, 1997), e o extrato seco desengordurado (ESD), pela diferença entre a porcentagem de gordura e extrato seco total (Tronco, 1997). Nitrogênio não-protéico, proteína verdadeira (obtida após precipitação com ácido tricloroacético) e proteína bruta foram determinados pelo método de Kjedahl (Silva et al., 1997). A porcentagem de caseína foi determinada pelo método de Walker, utilizando $\mathrm{NaOH}$ 0,1N e formaldeído (Fagundes, 1997) e o teor de lactose, por espectrofotometria por radiação infravermelha no equipamento Bentley 2000® (Fonseca \& Santos, 2000). A crioscopia do leite foi medida em Crioscópio Eletrônico Digital ITR MK540, fornecendo a leitura em Graus Horvet (Tronco, 1997).
Nas amostras de leite enviadas ao Serviço de Análise de Rebanhos Leiteiros (Sarle), da Universidade de Passo Fundo (UPF), realizou-se a contagem de células somáticas (CCS) por citometria de fluxo (Somacount 300, da Bentley Instruments, Inc.).

Foram coletadas amostras de todos os alimentos utilizados no dia da coleta. As amostras de concentrado foram retiradas dos sacos ou silos, dependendo da forma de armazenamento, e as da silagem, coletadas em diversos pontos, diretamente do silo, até obter uma amostra composta com, aproximadamente, $500 \mathrm{~g}$ da quantidade utilizada no dia da visita. As amostras de pasto foram coletadas do piquete em que as vacas se encontravam no dia da visita, por coleta manual, simulando o pastejo, e atravessando em ziguezague toda a área. As amostras foram colocadas em saco plástico, acondicionadas em caixa térmica com gelo, e mantidas resfriadas até o dia seguinte, quando se processou a pré-secagem. Anotaram-se as informações sobre a formulação da ração a partir de dados fornecidos pelo fabricante, quantidades de volumoso e concentrado fornecidas, tempo de pastejo, situação da pastagem, aspectos organolépticos da silagem, cuidados com plantio e adubação. Apenas as amostras coletadas nos meses de outubro, novembro, dezembro, fevereiro, abril, junho e agosto foram analisadas.

Realizou-se a pré-secagem das amostras, em estufa com circulação forçada de ar $\left(60^{\circ} \mathrm{C}\right)$, por 48 horas, seguida dos procedimentos de moagem e análises de matéria seca, de matéria mineral e de proteína bruta (PB), segundo a AOAC (1975), de fibra em detergente ácido (FDA) e de fibra em detergente neutro (FDN), consoante Goering \& Van Soest (1970).

Os dados mensais climatológicos (Tabela 1), usados neste trabalho foram obtidos na Estação Agroclimatológica de Pelotas (Boletim Agroclimatológico, 1999 e 2000).

O monitoramento do rebanho foi realizado em cada visita. Registraram-se condição corporal, número de dias após o parto, idade, quantidade de leite produzido, ordem de lactação e raça das vacas em lactação. Anotaram-se as condições higiênicas de ordenha, instalações e equipamentos em formulários.

Coletaram-se amostras com $250 \mathrm{~mL}$ de água de consumo dos animais ou água de limpeza, no início, meio e final do experimento para medir pH (método potenciométrico), grau de dureza (método de Bourdry), cloretos, nitratos (método de Moohr) e

\section{R. Bras. Zootec., v.33, n.6, p.1531-1543, 2004}


nitritos (através de eletrodo sensível) (Cunha et al., 1984). Outra amostra foi colocada em frasco estéril, com adição de tiosulfato, para contagem padrão de microrganismos aeróbios mesófilos e determinação do Número Mais Provável (NMP) de coliformes totais e fecais (Brasil,1999). Os dados foram confrontados com os parâmetros aceitos por Brasil (1995), segundo a Resolução do CONAMA para Águas Classe III - Águas destinadas à irrigação de culturas arbóreas, cerelíferos e forrageiras, à dessedentação de animais e ao abastecimento doméstico.

O delineamento experimental adotado foi o completamente casualizado, em arranjo fatorial desbalanceado, considerando como fatores os meses do ano $(n=11)$ e os sistemas de produção $(n=3)$. As UPL dentro de cada sistema foram as unidades experimentais: sistema especializado $(n=4)$, sistema semi-especializado $(n=4)$ e sistema não-especializado $(\mathrm{n}=2)$. As variáveis dependentes analisadas foram: porcentagens de proteína bruta do leite $(n=104)$, caseína $(n=104)$, proteína verdadeira do leite $(n=81)$, nitrogênio não-protéico $(\mathrm{n}=81)$, gordura do leite $(\mathrm{n}=104)$, lactose $(\mathrm{n}=86)$, sólidos totais $(\mathrm{n}=104)$, sólidos desengordurados $(n=104)$, crioscopia $(n=88)$, acidez $(n=96)$, produção de leite $(n=104)$, porcentagem de mastite $(\mathrm{n}=104)$, contagem de células somáticas $(n=84)$, porcentagens de PB do concentrado $(n=75)$, FDA concentrado $(n=75)$, FDN do concentrado $(\mathrm{n}=75)$, PB da pastagem $(\mathrm{n}=58)$, FDA da pastagem $(n=59)$, FDN da pastagem $(n=59)$. As porcentagens de PB, FDA e FDN da silagem não foram consideradas nas análises, em virtude do pequeno número de amostras, dado seu uso inconstante pela maior parte das UP. Os números desiguais de observações por variável dependente decorreram da perda de amostras. A produção de leite do tanque foi corrigida para $4,0 \%$ de gordura $[(0,4) \times$ (produção de leite $)+15$ (produção de leite x \%gordura/100)]. As variáveis expressas como porcentagem foram transformadas pela aplicação do arcoseno da raiz quadrada de seus valores percentuais e,

\begin{tabular}{|c|c|c|c|c|c|}
\hline Tabela 1 & \multicolumn{5}{|c|}{$\begin{array}{l}\text { Monthly values of historical (upper values) and 1999/2000 (lower values) for mean } \\
\text { temperature (MeT), minimal temperature (MiT), maximal temperature (MxT), rain fall (RF) } \\
\text { and number of rainy days (NRD) }\end{array}$} \\
\hline $\begin{array}{l}\text { Meses do ano } \\
\text { Months of year }\end{array}$ & $\mathrm{TM}\left({ }^{\circ} \mathrm{C}\right)$ & $\mathrm{TMi}\left({ }^{\mathrm{a}} \mathrm{C}\right)$ & $\mathrm{TMa}\left({ }^{\circ} \mathrm{C}\right)$ & $\mathrm{PP}(\mathrm{mm})$ & $\mathrm{NDP}$ \\
\hline Months of year & $\operatorname{MeT}\left({ }^{a} \mathrm{C}\right)$ & $\operatorname{MiT}\left({ }^{a} \mathrm{C}\right)$ & $\operatorname{MaT}\left({ }^{a} \mathrm{C}\right)$ & $R F(\mathrm{~mm})$ & $N R D$ \\
\hline $\begin{array}{l}\text { Setembro } \\
\text { September }\end{array}$ & $15,215,1$ & $11,611,2$ & $19,719,4$ & 113137 & $9,010,9$ \\
\hline $\begin{array}{l}\text { Outubro } \\
\text { October }\end{array}$ & $17,217,6$ & $14,013,2$ & $20,922,1$ & $92,094,6$ & 109,6 \\
\hline $\begin{array}{l}\text { Novembro } \\
\text { November }\end{array}$ & $19,119,7$ & $14,815,0$ & $24,524,4$ & $27,996,7$ & $7,09,6$ \\
\hline $\begin{array}{l}\text { Dezembro } \\
\text { December }\end{array}$ & $21,721,9$ & $17,817,2$ & $26,426,9$ & $75,391,9$ & $12,09,1$ \\
\hline $\begin{array}{l}\text { Fevereiro } \\
\text { February }\end{array}$ & $22,723,2$ & $18,618,7$ & $27,828,2$ & $67,1121,0$ & $7,010,9$ \\
\hline $\begin{array}{l}\text { Março } \\
\text { March }\end{array}$ & $20,721,6$ & $17,017,2$ & $25,626,7$ & $129,0113,0$ & $12,010,2$ \\
\hline $\begin{array}{l}\text { Abril } \\
\text { April }\end{array}$ & $19,618,4$ & $10,013,8$ & $25,123,7$ & $54,574,6$ & $12,07,8$ \\
\hline $\begin{array}{l}\text { Maio } \\
\text { May }\end{array}$ & $15,315,2$ & $12,210,6$ & $20,020,8$ & $241,283,9$ & $13,08,5$ \\
\hline $\begin{array}{l}\text { Junho } \\
\text { June }\end{array}$ & $14,812,6$ & $11,88,4$ & $19,417,9$ & $199,292,8$ & $10,09,7$ \\
\hline $\begin{array}{l}\text { Julho } \\
\text { July }\end{array}$ & $10,712,6$ & $7,38,6$ & $15,417,6$ & $144,8132,8$ & $8,010,7$ \\
\hline $\begin{array}{l}\text { Agosto } \\
\text { August }\end{array}$ & $12,413,5$ & $8,09,4$ & $18,218,3$ & $133,3137,6$ & $7,010,7$ \\
\hline
\end{tabular}

R. Bras. Zootec., v.33, n.6, p.1531-1543, 2004 
posteriormente, analisados (Markus, 1973). Os valores de contagem de células somáticas foram transformados pela aplicação do logaritmo base $10 \mathrm{e}$, posteriormente, analisados ( $\mathrm{Ng}$-Kwai-Hang et al., 1982). Também foram analisadas as variáveis dependentes relativas à qualidade da água: concentração de cloretos $(n=40)$, de nitrato $(n=40)$, de nitrito $(\mathrm{n}=40), \mathrm{pH}(\mathrm{n}=40)$, dureza $(\mathrm{n}=40)$, quantidade de microorganismos mesófilos $(n=30)$, coliformes totais $(n=30)$ e fecais $(n=30)$.

As variáveis dependentes foram submetidas à análise da variância, utilizando-se o procedimento GLM - General Linear Models, quadrados mínimos, considerando os efeitos de meses, sistemas e interação entre meses e sistemas. A separação das médias relativas aos efeitos foi efetuada com a aplicação do lsmeans e DMS de Fisher. Foram verificadas correlações lineares (coeficiente de Pearson) entre produção de leite, CCS, porcentagem de mastite e lactose, por intermédio do procedimento CORR, do pacote estatístico SAS (SAS, 1989), a fim de verificar a tendência de associação entre variáveis e comparar estes resultados com a literatura. O nível de significância para rejeição da hipótese de nulidade foi de 0,05. Embora a análise estatística tenha sido feita com os valores transformados, os seus valores originais são apresentados nas tabelas que se seguem, para facilitar a interpretação. O modelo estatístico adotado é apresentado a seguir:

$$
\mathrm{Y}_{\mathrm{ijkl}}=\mathrm{U}+\mathrm{S}_{\mathrm{i}}+\mathrm{M}_{\mathrm{j}}+\mathrm{SM}_{\mathrm{ij}}+\mathrm{P}(\mathrm{S})_{\mathrm{k}(\mathrm{i})}+\mathrm{E}_{\mathrm{ijkl}}
$$

em que $Y_{i j k l}=$ observações realizadas em cada UPL $\mathrm{k}$, no sistema $\mathrm{i}$, no mês $\mathrm{j}$; $\mathrm{U}=$ média geral do experimento; $S_{i}=$ sistema de produção $(\mathrm{GL}=2)$; $\mathrm{M}_{\mathrm{j}}=$ meses do ano $(\mathrm{GL}=10) ; \mathrm{SM}_{\mathrm{ij}}=$ interação entre sistemas de produção e meses do ano $(\mathrm{GL}=20)$; $\mathrm{P}(\mathrm{S})_{\mathrm{k}}=$ UPL hierarquizada dentro de sistema $(\mathrm{GL}=21) ; \mathrm{E}_{\mathrm{ijkl}}=$ erro experimental $(\mathrm{GL}=56)$.

Apesar de o efeito de sistemas de produção ter sido considerado no modelo estatístico, os resultados relativos a este efeito não são apresentados neste trabalho, e serão abordados posteriormente em outro manuscrito. As principais diferenças entre os sistemas deveram-se ao tipo e à quantidade de alimentação fornecida e à presença ou não de forragem conservada. Outro aspecto bastante distinto entre os sistemas foi a condição de higiene durante a ordenha.

\section{Resultados e Discussão}

Não houve efeito significativo da interação entre meses e sistemas de produção sobre as variáveis dependentes, exceto para a porcentagem de proteína bruta do leite. No presente trabalho, serão apresentados os efeitos dos meses do ano sobre a produção e as características do leite.

A produção de leite corrigida para $4 \%$ de gordura (Tabela 2) não variou significativamente entre os meses estudados, estando de acordo com estudos de Barbosa et al. (1994), em Pernambuco. Provavelmente, o pequeno número de UPL, divididas em diferentes sistemas de produção, impediu a detecção de diferenças significativas. Porém, observou-se diferença significativa $(\mathrm{P}=0,0001)$ entre os sistemas de produção, com 16,38 L/vaca/dia para ES, 9,32 L/vaca/dia para $\mathrm{SE}$ e 5,91 L/vaca/dia para NE.

Numericamente, as médias de produção de leite comportaram-se conforme observações de Bitencourt et al. (2000), no Rio Grande do Sul, onde, em setembro, a produção de leite foi superior à dos demais meses com 14,58 L/vaca/dia, justificado pelo nível nutricional em que se encontravam os rebanhos (Stumpf et al., 2000). As menores produções (valores numéricos) ocorreram nos meses de março (10,14 L/vaca/dia) e abril (10,04 L/vaca/dia) (Figura 1), justificado pelo final do ciclo de produção de matéria seca das forragens de verão, com queda na sua qualidade

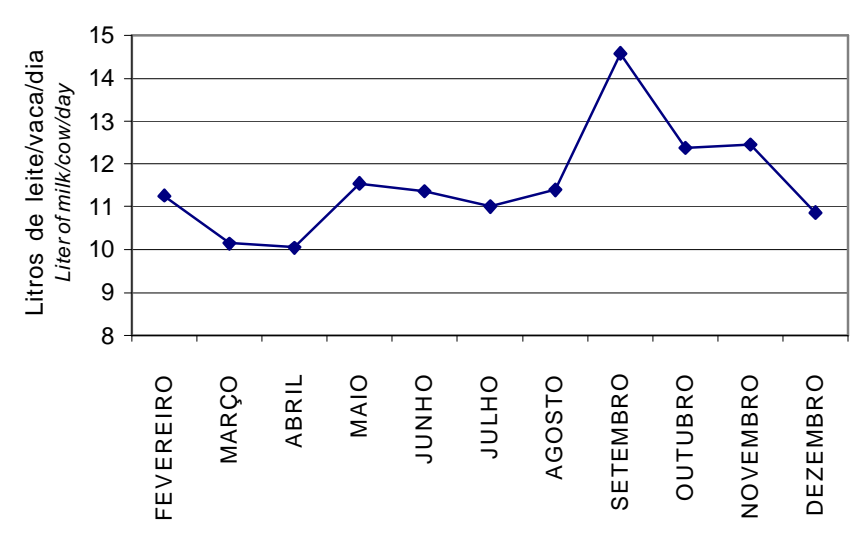

Figura 1 - Produção de leite corrigida a $4 \%$ de gordura de setembro de 1999 a agosto de 2000 .

Figure 1 - Milk production corrected for fat $4 \%$ from September 1999 to August 2000. 
Tabela 2 - Valores de probabilidade de rejeição da hipótese de nulidade $(a=0,05)$ dos efeitos dos meses do ano, sistemas de produção e interação entre meses e sistemas sobre a produção de leite corrigida a $4 \%$ de gordura, as características físico-químicas do leite, porcentagens de PB, FDA e FDN do concentrado e pastagem

Table 2 - P-values of null hypothesis rejection (a=.05) for the effects of months of year, production systems and interaction between months and systems on milk production corrected for fat $4 \%$, chemical-physical characteristics of the milk and percentages of CP, ADF and NDF for concentrate and pasture

\begin{tabular}{llcccc}
\hline Atributos & Meses & Sistemas & Sistemas x meses & Média & $\mathrm{CV}$ \\
Attributes & Months & Systems & Systems x months & Mean & $C V^{5}$ \\
& & & Desvio-padrão & \\
& & & Standart deviation
\end{tabular}

\begin{tabular}{|c|c|c|c|c|c|}
\hline Atributos do leite & & & & & \\
\hline Attributes of milk & & & & & \\
\hline Produção & 0,1046 & 0,0001 & 0,4724 & $11,48(1,91)$ & 16,65 \\
\hline Production & & & & & \\
\hline Crioscopia & 0,1503 & 0,0537 & 0,0527 & $-0,519(0,005)$ & 0,92 \\
\hline Crioscopy & & & & & \\
\hline Acidez & 0,0008 & 0,2541 & 0,5816 & $16,26(1,52)$ & 9,37 \\
\hline Acidity & & & & & \\
\hline Gordura & 0,7870 & 0,0004 & 0,2016 & $3,70(0,43)$ & 11,52 \\
\hline Fat & & & & & \\
\hline Lactose & 0,0023 & 0,0001 & 0,7684 & $4,44(0,16)$ & 3,51 \\
\hline Lactose & & & & & \\
\hline Proteína bruta & 0,0480 & 0,0001 & 0,0088 & $3,16(0,17)$ & 5,24 \\
\hline Crude protein & & & & & \\
\hline Proteína verdadeira & 0,0001 & 0,0726 & 0,1988 & $2,99(0,18)$ & 5,99 \\
\hline True protein & & & & & \\
\hline Caseína & 0,0007 & 0,6495 & 0,0808 & $2,30(0,27)$ & 11,78 \\
\hline Casein & & & & & \\
\hline $\mathrm{NNP}^{1}$ & 0,2069 & 0,2195 & 0,3056 & $0,028(0,006)$ & 22,73 \\
\hline$N P N^{1}$ & & & & & \\
\hline $\mathrm{EST}^{2}$ & 0,9235 & 0,0253 & 0,1292 & $12,20(0,70)$ & 5,71 \\
\hline$T S^{2}$ & & & & & \\
\hline $\mathrm{ESD}^{3}$ & 0,0405 & 0,3538 & 0,3231 & $8,51(0,46)$ & 5,43 \\
\hline$S N F^{3}$ & & & & & \\
\hline Mastite & 0,0102 & 0,0001 & 0,6747 & $56,61(11,61)$ & 20,51 \\
\hline Mastitis & & & & & \\
\hline CCS & 0,3387 & 0,0001 & 0,3715 & $461.000(195.000)$ & 42,31 \\
\hline$S C C^{4}$ & & & & & \\
\hline Atributos do concent & & & & & \\
\hline Attributes of concentrate & & & & & \\
\hline PB & 0,8039 & 0,0001 & 0,444 & $13,54(4,74)$ & 26,76 \\
\hline$C P$ & & & & & \\
\hline FDA & 0,2461 & 0,0001 & 0,1024 & $14,68(8,82)$ & 50,47 \\
\hline$A D F$ & & & & & \\
\hline FDN & 0,3174 & 0,0042 & 0,4219 & $33,26(9,56)$ & 25,66 \\
\hline$N D F$ & & & & & \\
\hline Atributos da pastager & & & & & \\
\hline Attributes of pasture & & & & & \\
\hline PB & 0,0003 & 0,5861 & 0,4688 & $9,16(3,17)$ & 24,46 \\
\hline$C P$ & & & & & \\
\hline FDA & 0,0035 & 0,2606 & 0,4838 & $31,04(7,42)$ & 20,31 \\
\hline$A D F$ & & & & & \\
\hline FDN & 0,0001 & 0,2179 & 0,5362 & $54,47(14,57)$ & 17,83 \\
\hline$N D F$ & & & & & \\
\hline
\end{tabular}

${ }^{1}$ Nitrogênio não-protéico (Non protein nitrogen).

${ }^{2}$ Sólidos totais (Total solids).

3 Sólidos não-gordurosos (Defated solids).

${ }^{4}$ Contagem de células somáticas (Somatic cell counts).

${ }^{5}$ Coeficiente de variação (\%) (Coefficient of variation). 
(Tabela 3), pela ausência ou limitado uso de forragem conservada e a não disponibilidade das forrageiras cultivadas de estação fria, a maioria em fase de implantação ou início de desenvolvimento.

No entanto, este resultado difere de Ribas et al. (1996), que, em estudos no Paraná por 18 anos, analisaram 23.454 lactações e encontraram maiores produções de leite no outono e verão.

A crioscopia não variou entre os meses estudados, apresentando média de $-0,518^{\circ} \mathrm{C}$ (Tabela 2). Estes resultados diferem dos de Rodas et al. (1999), que observaram variações durante os meses do ano, atribuindo como causas os fatores climáticos e nutricionais.

Os teores de gordura bruta, nitrogênio não-protéico (NNP), extrato seco total não variaram entre os meses estudados (Tabela 4), o que foi semelhante aos resultados encontrados por Batalha \& Benedet (2000), na região serrana de Santa Catarina.

$\mathrm{O}$ teor de proteína verdadeira $(\mathrm{P}=0,0001)$ variou entre os meses do ano, sendo superior em outubro e novembro e inferior em fevereiro (Tabela 4). Isto pode ser explicado pela melhor oferta de forragem (Fredeen, 1996) nos meses de primavera e pela restrição alimentar e perda da qualidade do volumoso nos meses mais quentes e de menor precipitação. No presente trabalho, observam-se menores valores de FDN e FDA e maiores níveis de PB na pastagem, em setembro e outubro em relação aos demais meses da estação quente (Tabela 3). Observa-se também diminuição dos valores de precipitação pluviométrica a partir de novembro, o que pode ter contribuído para restringir quantitativamente o consumo de pasto (Tabela 1).

A melhoria do nível nutricional pode aumentar a produção de ácido propiônico, com um efeito poupador nos aminoácidos no metabolismo intermediário, elevando a quantidade dos aminoácidos disponíveis para síntese protéica na glândula mamária. Aumento na concentração de proteína do leite é obtido quando se eleva sua concentração na alimentação, resultando em aumento da energia disponível (Fredeen, 1996).

Incremento no consumo de energia pode acarretar economia dos aminoácidos (caso haja um suporte adequado na dieta), que podem ser usados na gliconeogenese, aumentando seu suprimento para a glândula mamária. O animal metabolizaria uma maior proporção de aminoácidos glicogênicos, no fígado, para a síntese de glicose, quando se encontra em restrição alimentar, em decorrência, principalmente,

Tabela 3 - Valores médios da composição bromatológica (\%) dos alimentos fornecidos às vacas em lactação durante alguns meses do período experimental

Table 3 - Mean values for chemical composition (\%) of forages and concentrates offered to the cows during some months of experiment period

\begin{tabular}{|c|c|c|c|c|c|c|c|c|c|}
\hline & & & & & & $\begin{array}{l}\text { Meses } \\
\text { Months }\end{array}$ & & & \\
\hline & & $\begin{array}{l}\text { Setembro } \\
\text { September }\end{array}$ & $\begin{array}{c}\text { Outubro } \\
\text { October }\end{array}$ & $\begin{array}{c}\text { Novembro } \\
\text { November }\end{array}$ & $\begin{array}{l}\text { Dezembro } \\
\text { December }\end{array}$ & $\begin{array}{c}\text { Fevereiro } \\
\text { February }\end{array}$ & $\begin{array}{l}\text { Abril } \\
\text { April }\end{array}$ & $\begin{array}{c}\text { Junho } \\
\text { June }\end{array}$ & $\begin{array}{c}\text { Agosto } \\
\text { August }\end{array}$ \\
\hline Concentrado & $\mathrm{FDN}^{1}$ & & & & & & & & \\
\hline Concentrate & $N D F$ & $34,93 \mathrm{a}$ & $44,62^{\mathrm{a}}$ & $32,20 \mathrm{a}$ & $37,10 \mathrm{a}$ & $27,60 \mathrm{a}$ & $34,80 \mathrm{a}$ & $32,30 \mathrm{a}$ & $33,10 \mathrm{a}$ \\
\hline & $\mathrm{FDA}^{2}$ & $18,85 \mathrm{a}$ & $13,80^{\mathrm{a}}$ & $13,30 \mathrm{a}$ & $13,80 \mathrm{a}$ & $14,00 \mathrm{a}$ & $14,90 \mathrm{a}$ & $13,20 \mathrm{a}$ & $13,70 \mathrm{a}$ \\
\hline & $\begin{array}{l}\mathrm{A} D F \\
\mathrm{~PB}^{3}\end{array}$ & $16,85 a$ & $9,50^{\mathrm{a}}$ & $11,10 \mathrm{a}$ & $14,00 \mathrm{a}$ & $12,90 \mathrm{a}$ & $13,90 \mathrm{a}$ & $12,80 \mathrm{a}$ & $13,80 \mathrm{a}$ \\
\hline & $C P$ & & & & & & & & \\
\hline Pasto & FDN & $46,16 c$ & $49,85 \mathrm{c}$ & $72,67 \mathrm{a}$ & 65,76ab & $61,90 \mathrm{~b}$ & $58,00 \mathrm{bc}$ & $41,70 \mathrm{c}$ & $43,82 \mathrm{c}$ \\
\hline Pasture & $N D F$ & & & & & & & & \\
\hline & FDA & $21,60 \mathrm{c}$ & $30,10 \mathrm{bc}$ & $37,43 a$ & 32,97ab & 32,99ab & 33,33ab & $24,70 \mathrm{c}$ & $28,71 b c$ \\
\hline & $\begin{array}{l}A D F \\
\mathrm{~PB}^{3} \\
C P\end{array}$ & $12,94 \mathrm{a}$ & $9,12 \mathrm{~cd}$ & $7,86 \mathrm{~cd}$ & $6,99 d$ & $7,35 \mathrm{~d}$ & $7,80 \mathrm{~d}$ & $11,97 \mathrm{ab}$ & $9,97 \mathrm{~b}$ \\
\hline
\end{tabular}

a,b,c,d: médias, na mesma linha, seguidas por letras distintas diferem $(P<0,05)$ entre si segundo o DMS Fisher.

$a, b, c, d$ : means in the same row fololwed by distinct letters are different according to DMS Fisher test $(P<.05)$.

1 Fibra em detergente neutro, valores expressos como porcentagem da matéria seca.

1 Neutral detergent fiber, values as percentage of dry matter.

2 Fibra em detergente ácido, valores expressos como porcentagem da matéria seca.

2 Acid detergent fiber, values as percentage of dry matter.

3 Proteína bruta, valores expressos como porcentagem da matéria seca.

3 Crude protein, values as percentage of dry matter.

R. Bras. Zootec., v.33, n.6, p.1531-1543, 2004 
da restrição de suprimento de propionato (Mackle et al., 1999). Fredeen (1996) demonstram que a substituição de silagem de milho por pastagem de boa qualidade leva ao aumento na produção de proteína, pela maior digestibilidade da dieta e maior suporte de nutrientes.

Houve interação entre meses do ano e sistemas para o teor de proteína bruta (Tabela 2). O teor de proteína bruta, no sistema ES, diferiu entre os meses de setembro e outubro, enquanto no sistema SE os valores diferiram entre outubro e fevereiro. Em ambos os sistemas, observou-se que a proteína bruta apresentou maiores valores em outubro e menores em setembro, para o sistema ES, e em fevereiro, para o sistema SE (Tabela 5). Houve alagamento nas pastagens de uma das unidades produtoras do sistema ES, comprometendo o pastejo no mês de setembro. As propriedades do sistema SE foram prejudicadas pela estiagem e, por não possuir forragem conservada, reduziram a quantidade fornecida de volumoso no mês de fevereiro. Estes resultados diferem do trabalho de Durr et al. (1999), em Santa Rosa-RS, onde o teor de proteína não apresentou tendência de variação.

No mês de setembro, o valor de PB ficou abaixo dos valores estipulados pela Normativa 51 (Brasil, 2002), e, em fevereiro, encontra-se no limite aceito de 2,9\% de PB para o leite. Estes meses deveriam receber maior atenção na implantação de estratégias nutricionais e de manejo, para evitar a rejeição deste leite pela indústria. Na Tabela 1, observa-se um volume de precipitações acima do normal no mês de setembro, levando a alagamento nas regiões mais baixas, comprometendo o pastejo, e posteriormente à estiagem de fevereiro, afetando as áreas de pastagem de verão.

Tabela 4 - Valores médios da composição química do leite, de acordo com os meses (setembro/99 a agosto/2000). Os valores de gordura, lactose, proteína verdadeira, caseína, nitrogênio não-protéico (NNP), estrato seco total (EST), estrato seco desengordurado (ESD) são expressos em porcentagem e de acidez, em graus Dornic

Table 4 - Mean values of chemical milk composition according the months (September 199 to August/2000) Values of fat, lactose, true protein, casein, non protein nitrogen (NPN), total solids (TS), solids non fat ((SNF) are expressed as percentage and acidity as Dornic degrees

\begin{tabular}{|c|c|c|c|c|c|c|c|c|}
\hline $\begin{array}{l}\text { Meses do ano } \\
\text { Months of year }\end{array}$ & $\begin{array}{c}\text { Gordura } \\
\text { Fat }\end{array}$ & $\begin{array}{c}\text { Lactose } \\
\text { Lactose }\end{array}$ & $\begin{array}{c}\text { Proteína } \\
\text { verdadeira } \\
\text { True protein }\end{array}$ & $\begin{array}{c}\text { Caseína } \\
\text { Casein }\end{array}$ & $\begin{array}{l}\text { NNP } \\
N P N\end{array}$ & $\begin{array}{c}\text { EST } \\
T S\end{array}$ & $\begin{array}{l}\text { ESD } \\
S N F\end{array}$ & $\begin{array}{c}\text { Acidez }\left({ }^{\circ} \mathrm{D}\right) \\
\text { Acidity }\end{array}$ \\
\hline $\begin{array}{l}\text { Setembro } \\
\text { September }\end{array}$ & $3,50 \mathrm{a}$ & $\mathrm{ND}^{1}$ & ND & $2,25 \mathrm{ab}$ & ND & $12,11 \mathrm{a}$ & 8,61 abcd & ND \\
\hline $\begin{array}{l}\text { Outubro } \\
\text { October }\end{array}$ & $3,62 \mathrm{a}$ & ND & $3,39 a$ & $2,53 \mathrm{a}$ & $0,033 \mathrm{a}$ & $12,26 \mathrm{a}$ & $8,64 \mathrm{ab}$ & $15,40 \mathrm{~b}$ \\
\hline $\begin{array}{l}\text { Novembro } \\
\text { November }\end{array}$ & $3,74 a$ & $4,54 \mathrm{a}$ & $3,25 a$ & $2,49 a$ & $0,026 a$ & $12,29 \mathrm{a}$ & 8,56bcd & $14,95 \mathrm{c}$ \\
\hline $\begin{array}{l}\text { Dezembro } \\
\text { December }\end{array}$ & $3,53 \mathrm{a}$ & $4,52 \mathrm{a}$ & $3,02 b$ & $2,32 \mathrm{ab}$ & $0,030 \mathrm{a}$ & $12,40 \mathrm{a}$ & $8,87 \mathrm{a}$ & $15,40 \mathrm{~b}$ \\
\hline $\begin{array}{l}\text { Fevereiro } \\
\text { February }\end{array}$ & $3,86 a$ & $4,47 \mathrm{a}$ & $2,70 \mathrm{c}$ & $2,06 b$ & $0,030 \mathrm{a}$ & $12,04 \mathrm{a}$ & $8,18 \mathrm{~d}$ & $17,08 \mathrm{a}$ \\
\hline $\begin{array}{l}\text { Março } \\
\text { March }\end{array}$ & $3,69 \mathrm{a}$ & $4,30 \mathrm{~b}$ & $2,98 b$ & $2,47 a$ & $0,024 \mathrm{a}$ & $12,08 \mathrm{a}$ & 8,39bcd & $15,78 b$ \\
\hline $\begin{array}{l}\text { Abril } \\
\text { April }\end{array}$ & $3,77 \mathrm{a}$ & $4,33 b$ & $2,78 b c$ & $2,49 a$ & $0,028 \mathrm{a}$ & $12,06 \mathrm{a}$ & $8,29 \mathrm{~cd}$ & $16,75 \mathrm{a}$ \\
\hline $\begin{array}{l}\text { Maio } \\
\text { May }\end{array}$ & $3,71 \mathrm{a}$ & $4,34 b$ & $2,85 b$ & $2,31 \mathrm{ab}$ & $0,024 a$ & $12,23 \mathrm{a}$ & $8,52 \mathrm{bcd}$ & $16,57 \mathrm{a}$ \\
\hline $\begin{array}{l}\text { Junho } \\
\text { June }\end{array}$ & $3,73 a$ & $4,47 \mathrm{a}$ & $3,03 b$ & $2,06 b$ & $0,029 \mathrm{a}$ & $12,22 \mathrm{a}$ & $8,49 \mathrm{bcd}$ & $16,40 \mathrm{a}$ \\
\hline $\begin{array}{l}\text { Julho } \\
\text { July }\end{array}$ & $3,63 a$ & $4,42 \mathrm{ab}$ & $2,87 \mathrm{~b}$ & $2,06 b$ & $0,030 \mathrm{a}$ & $12,04 \mathrm{a}$ & $8,42 \mathrm{bcd}$ & $17,00 \mathrm{a}$ \\
\hline $\begin{array}{l}\text { Agosto } \\
\text { August }\end{array}$ & $3,80 \mathrm{a}$ & $4,55 a$ & $2,85 \mathrm{bc}$ & $2,31 \mathrm{ab}$ & $0,029 a$ & $12,41 \mathrm{a}$ & $8,61 \mathrm{abc}$ & $17,50 \mathrm{a}$ \\
\hline $\begin{array}{l}\text { Média } \\
\text { Mean }\end{array}$ & 3,69 & 4,44 & 2,97 & 2,30 & 0,028 & 12,20 & 8,51 & 16,26 \\
\hline
\end{tabular}


Os teores de extrato seco desengordurado $(\mathrm{P}=0,0404)$ diferiram entre os meses (Tabela 4), sendo a maior média $(8,87 \%)$ observada em dezembro e a menor $(8,17 \%)$ em fevereiro, graças à provável influência da redução nos teores energéticos da dieta (Laben, 1963) e de restrição da oferta de pastagem decorrente da estiagem (Tabela 1) observada no último período. Nos meses de fevereiro e abril, os valores de ESD apresentaram-se abaixo dos permitidos (mínimo de 8,4\%) pela Normativa 51 (Brasil, 2002).

A porcentagem de caseína foi menor em junho, julho e fevereiro e maior em outubro, novembro, março e abril (Tabela 4). Os meses de menor síntese protéica corresponderam ao período de menor oferta da forragem, e os meses de março e abril registraram um declínio bastante acentuado na produção de leite, o que leva ao aumento da concentração dos componentes de leite (Lacy Hulbert et al., 1999), refletindo nos seus percentuais.

O período da primavera é caracterizado por melhor qualidade protéica e maior disponibilidade de forragem, em função das espécies utilizadas na região serem predominantemente azevém anual (Lolium multiflorum) e leguminosas como cornichão (Lotus corniculatus) e trevos (Trifolium spp). Mackle et al. (1999) encontraram maiores valores para caseína em pastagem de verão e utilização de concentrado, e a concentração de caseína declinou quando houve restrição de pasto. Na região sul do Rio Grande do Sul, em propriedades que utilizam leguminosas consorciadas com gramíneas de inverno, observa-se o seu maior vigor no período inicial de primavera.

A lactose é o componente que menos varia no leite bovino (González, 2001), porém houve diferença sazonal nas porcentagens de lactose (Tabela 2), observando-se os menores valores nos meses de março, abril e maio (Tabela 4). Mackle et al. (1999) e Bruhn \& Franke (1977), entretanto, não encontraram variação ao longo do ano. Março e abril foram os meses de menor produção de leite (Figura 1) e maio, um dos meses com maior porcentagem de mastite (Tabela 6). Houve variação entre os sistemas estudados, com $4,57 \%$ para o sistema ES, $4,46 \%$ para o SE e $4,15 \%$ para o NE. Observou-se, durante este experimento, correlação positiva entre produção de leite e lactose $(\mathrm{r}=0,59 ; \mathrm{P}=0,0001)$ e negativa entre mastite $(\mathrm{r}=-0,412 ; \mathrm{P}=0,0001)$ e CCS $(\mathrm{r}=-0,653$; $\mathrm{P}=0,0001)$. Kitchen (1981) sugeriu que a concentração de lactose no leite poderia ser utilizada como critério para detecção de mastite.

Mudanças na concentração de lactose, durante a mastite, podem ocorrer graças à passagem de lactose do leite para o sangue, o que pode ser comprovado pelas concentrações elevadas de lactose no sangue e na urina de vacas com mastite (Shuster, 1991). Adicionalmente, a lesão tecidual ocasionada pela mastite reduz a capacidade de síntese de lactose pelo epitélio glandular, o que afeta significativamente a quantidade de leite produzida, devido ao papel central da lactose como agente regulador osmótico do volume de leite (Mephan, 1983; Harmon, 1994).

A gordura não variou significativamente entre os

Tabela 5 - Valores mensais médios da porcentagem de proteína bruta no leite oriundo de sistemas especializado (ES), semi-especializado (SE) e não especializado (NE) de acordo com o mês de coleta do leite (setembro/99 a agosto/ 2000)

Table 5 - Monthly average percentage of crude protein in the milk of specialized system (S), partially specialized system (PS) and not specialized system (NS) according to months of milk collection (September) 99 to August/2000)

\begin{tabular}{|c|c|c|c|}
\hline \multirow{3}{*}{$\begin{array}{l}\text { Meses do ano } \\
\text { Months of year }\end{array}$} & \multicolumn{3}{|c|}{$\begin{array}{l}\text { Sistemas } \\
\text { Systems }\end{array}$} \\
\hline & $\mathrm{ES}$ & $\mathrm{SE}$ & $\mathrm{NE}$ \\
\hline & $S P$ & $S E$ & $N S$ \\
\hline Setembro & $2,84 b$ & $3,02 \mathrm{ab}$ & $2,81 \mathrm{a}$ \\
\hline \multicolumn{4}{|l|}{ September } \\
\hline Outubro & $3,57 \mathrm{a}$ & $3,69 a$ & $3,47 \mathrm{a}$ \\
\hline \multicolumn{4}{|l|}{ October } \\
\hline Novembro & $3,39 \mathrm{ab}$ & $3,48 \mathrm{ab}$ & $3,36 \mathrm{a}$ \\
\hline \multicolumn{4}{|l|}{ November } \\
\hline Dezembro & $3,15 \mathrm{ab}$ & $3,17 \mathrm{ab}$ & $3,41 \mathrm{a}$ \\
\hline \multicolumn{4}{|l|}{ December } \\
\hline Fevereiro & $2,92 \mathrm{ab}$ & $2,85 b$ & $2,97 \mathrm{a}$ \\
\hline \multicolumn{4}{|l|}{ February } \\
\hline Março & $3,14 \mathrm{ab}$ & $3,01 \mathrm{ab}$ & $3,37 \mathrm{a}$ \\
\hline \multicolumn{4}{|l|}{ March } \\
\hline Abril & $3,05 \mathrm{ab}$ & $2,95 \mathrm{ab}$ & $3,60 \mathrm{a}$ \\
\hline \multicolumn{4}{|l|}{ April } \\
\hline Maio & $2,89 \mathrm{ab}$ & $2,92 \mathrm{ab}$ & $3,39 \mathrm{a}$ \\
\hline \multicolumn{4}{|l|}{ May } \\
\hline Junho & $3,23 \mathrm{ab}$ & $3,26 a b$ & $3,18 \mathrm{a}$ \\
\hline \multicolumn{4}{|l|}{ June } \\
\hline Julho & $3,18 \mathrm{ab}$ & $3,00 \mathrm{ab}$ & $3,06 \mathrm{a}$ \\
\hline \multicolumn{4}{|l|}{ July } \\
\hline Agosto & $3,07 \mathrm{ab}$ & $3,05 \mathrm{ab}$ & $3,05 \mathrm{a}$ \\
\hline \multicolumn{4}{|l|}{ August } \\
\hline Média do ano & 3,13 & 3,13 & 3,24 \\
\hline Mean of year & & & \\
\hline
\end{tabular}

a,b,c = Médias seguidas por letras distintas na mesma coluna diferem pelo teste DMS Fisher $(\mathrm{P}<0,05)$.

$a, b, c=$ Means followed by different letters at same column are different $(P<.05)$, according to DMS Fisher test. 
meses estudados. Este resultado difere dos encontrados por Dürr et al.(1999), no Rio Grande do Sul, com percentuais de gordura superiores no inverno, comparados às demais épocas do ano. A gordura é o componente do leite mais variável (González, 2001). Porém, sabe-se, também, que há forte relação negativa entre a gordura e a produção de leite (Carvalho et al., 1999), e esta última não demonstrou variação significativa entre os meses. Incremento no volume de leite produzido leva à diluição da gordura, mesmo que sua síntese esteja favorecida por fatores alimentares, que também aumentam a produção de leite, resultando em redução nos percentuais de gordura, quando há maior volume de leite.

A acidez titulável $(\mathrm{P}=0,0008)$ foi menor em novembro (Tabela 4), relacionada à maior porcentagem de mastite, tornando o leite mais alcalino (Fagundes, 1997). Provavelmente, os teores de sódio e de cloro foram elevados no leite produzido por animais com mastite, pois as concentrações no sangue são normalmente maiores que as do leite (Santos, 2001).
A porcentagem de mastite $(\mathrm{P}=0,00079)$ variou entre os meses do ano, sendo maior em novembro $(63,42 \%)$ e maio $(62,21 \%)$, conforme Tabela 6 , e menor em setembro $(45,35 \%)$, parcialmente explicada pela melhor qualidade nutricional a que os rebanhos foram submetidos, promovendo melhor imunidade (Fonseca \& Santos, 2000), e pela melhor possibilidade de controle higiênico na ordenha, em função de temperaturas mais amenas e médias precipitações pluviométricas (Allore et al., 1998). Durante os meses de novembro e maio, ocorreram, respectivamente, temperaturas e precipitações elevadas (Tabela 1), o que pode favorecer a maior incidência de mastite (Harmon, 1994), além da variação entre os sistemas de produção $(\mathrm{ES}=48,51 \% ; \mathrm{SE}=57,15 \%$ e $\mathrm{NE}=71,73 \%)$.

A contagem de células somáticas ( $\mathrm{P}=0,3554)$ não apresentou diferença significativa entre os meses do ano (Tabela 6), semelhantemente ao trabalho de Rosenfeld et al. (2000). Este resultado diferiu dos achados de Garcia \& Holmes (2001), em que a CCS

Tabela 6 - Valores mensais médios da \% de quartos reagentes (teste da caneca e/ou CMT) e mastite e número de células somáticas

Table 6 - Monthly average for incidence of mastitis and somatic cell counts

\begin{tabular}{|c|c|c|}
\hline $\begin{array}{l}\text { Meses do ano } \\
\text { Months of year }\end{array}$ & $\begin{array}{l}\text { Incidência de mastite } \\
\text { Incidence of mastitis }\end{array}$ & $\begin{array}{l}\text { Número de células somáticas }(\mathrm{x} 1000 / \mathrm{mL}) \\
\text { Somatic cell number }(\times 1000 / \mathrm{mL})\end{array}$ \\
\hline Setembro & $45,35 b$ & ND \\
\hline September & & \\
\hline Outubro & $49,82 b$ & $\mathrm{ND}^{1}$ \\
\hline October & & \\
\hline Novembro & $63,42 \mathrm{a}$ & $485 \mathrm{a}$ \\
\hline November & & \\
\hline Dezembro & $58,47 \mathrm{ab}$ & $307 a$ \\
\hline December & & \\
\hline Fevereiro & $60,22 \mathrm{ab}$ & $389 a$ \\
\hline Februry & & \\
\hline Março & $59,71 \mathrm{ab}$ & $380 \mathrm{a}$ \\
\hline March & & \\
\hline Abril & $58,75 \mathrm{ab}$ & $486 a$ \\
\hline April & & \\
\hline Maio & $62,21 \mathrm{a}$ & $693 a$ \\
\hline May & & \\
\hline Junho & $60,74 \mathrm{ab}$ & $450 \mathrm{a}$ \\
\hline June & & \\
\hline Julho & $51,10 \mathrm{~b}$ & $447 \mathrm{a}$ \\
\hline July & & \\
\hline Agosto & $48,73 b$ & $469 a$ \\
\hline August & & \\
\hline
\end{tabular}

R. Bras. Zootec., v.33, n.6, p.1531-1543, 2004 
foi maior na primavera que no outono. A variação não-significativa da CCS, em oposição aos resultados da incidência de mastite, pode ser atribuída, em parte, à forma de amostragem, em que a coleta de leite foi feita do tanque resfriador; para incidência de mastite, foram coletadas amostras de leite dos quartos das vacas lactantes. Os valores encontrados satisfazem as três primeiras fases do regulamento técnico de identidade e qualidade do leite cru refrigerado (Brasil, 2002) para CCS, mas, para a última parte do programa, apenas os meses de dezembro, fevereiro e março, estariam dentro das exigências da Normativa 51. Para os sistemas, houve variação, com valores superiores para NE (907.000 células/mL), intermediário para SE (437.000 células/mL) e inferior para ES (261.000 células/mL).

A qualidade da água variou entre os meses e entre os sistemas, porém não houve interação entre esses fatores (Tabela 7). A contagem de mesófilos foi maior em novembro ( $47268 \mathrm{ufc} / \mathrm{mL})$, seguida pelos meses de março ( $4451 \mathrm{ufc} / \mathrm{mL})$ e agosto $(387 \mathrm{ufc} / \mathrm{mL})$. Ainda que os demais parâmetros da água não tenham sido afetados estatisticamente pelos meses ou pela interação entre meses e sistemas de produção, verificou-se que uma UPL do sistema especializado e outra do não-especializado apresentaram valores superiores aos recomendados por Brasil (1995) para coliformes totais em dois dos três meses de coleta. Em relação à composição química, observou-se que duas UPL do sistema especializado apresentaram água com valores de dureza superiores aos recomendados por Brasil (1995) em dois dos quatro meses de coletas. Em relação à concentração de cloretos, duas UPL do sistema especializado e uma do não-especializado apresentaram valores excessivos em dois dos quatro meses de coleta (Brasil, 1995). Em relação aos nitratos, duas UPL pertencentes aos sistemas especializado e semiespecializado apresentaram teores excessivos de nitratos em pelo menos um dos quatro meses de coleta. Todos os sistemas apresentaram água com valores de $\mathrm{pH}$ abaixo de 6,0 em pelo menos três dos quatro meses de coleta (Brasil, 1995). Estes resultados sugerem que a qualidade da água pode, em diversos momentos do ano, afetar a saúde dos animais ou a vida útil dos equipamentos.

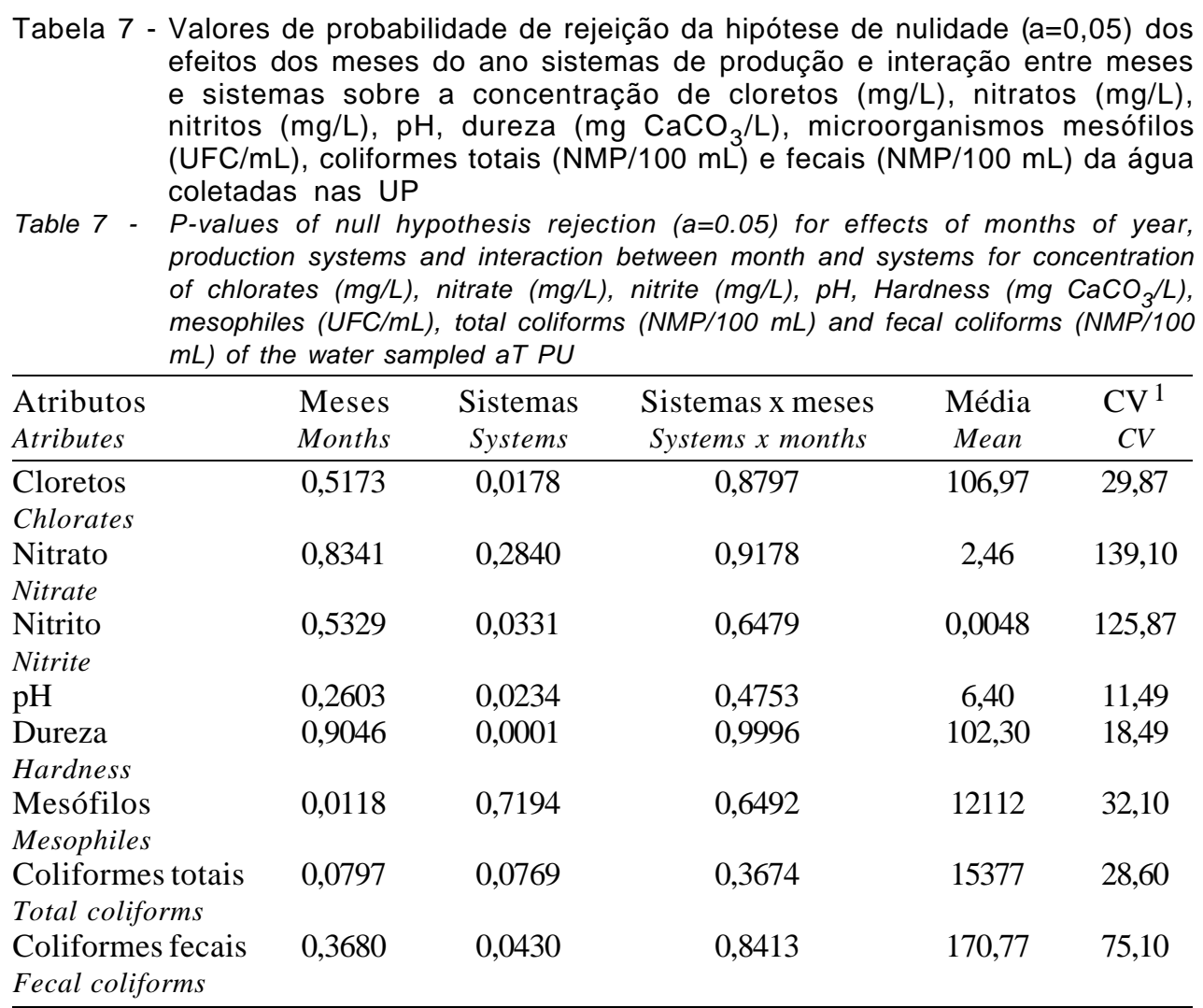

R. Bras. Zootec., v.33, n.6, p.1531-1543, 2004 


\section{Conclusões}

Os meses do ano afetaram a composição química do leite e a ocorrência de mastite, o que foi relacionado, respectivamente, às variações de disponibilidade e qualidade dos alimentos e às condições climáticas favoráveis aos microrganismos. De modo geral, o melhor nível nutricional verificado na primavera permitiu os maiores valores das frações nitrogenadas do leite. A precipitação excessiva foi relacionada aos maiores índices de mastite, porém a CCS esteve dentro dos parâmetros exigidos pela Normativa 51, para as três primeiras fases do Regulamento. Embora a qualidade de água não tenha sido estatisticamente afetada pelos meses, pode-se inferir que é necessário maior monitoramento e cuidado com a água de bebida e de limpeza dos equipamentos.

\section{Literatura Citada}

ALlORE, H.G.; ERB, H.N.; SCHRUBEN, L.W. et al. A simulation of strategeis to lower bulk tank somatic cell count below 500000 per milliliter. Journal of Dairy Science, v.81, p.694-702, 1998.

ASSOCIATION OF OFFICIAL ANALITICAL CHEMIST AOAC. Official methods of analysis. 12.ed. Washigton, D.C.: $1975.1094 p$.

BARBOSA, P.F.; COSTA, J.L.; CRUZ, G.M. et al. Causas da variação da produção de leite e duração do período de lactação em vacas mestiças Europeu X Zebu. In: REUNIÃO ANUAL DA SOCIEDADE BRASILEIRA DE ZOOTECNIA, 33., 1996, Fortaleza. Anais... Fortaleza: Sociedade Brasileira de Zootecnia, 1996.

BARBOSA, S.B.; MILAGRES, J.C.; REGAZZI, A.J. et al. Estudo da produção de leite em rebanhos holandeses, no Estado de Pernambuco. Revista da Sociedade Brasileira de Zootecnia, v.23, n.3, p.422-432, 1994.

BATALHA, C.P.; BENEDET, H.D. Características do leite produzido na região serrana do Estado de Santa Catarina, Brasil. Revista do Instituto de Laticínios "Candido Tostes", v.55, n.315, p.166-173, 2000.

BITTENCOURT, D.; STUMPF, W.J.; XAVIER, S.S. et al. A importância da atividade leiteira na economia agropecuária do RGS In: STUMPF, W.J.; BITTENCOURT, D.; GOMES, J.F. et al. (Eds.) Sistemas de pecuária de leite: uma visão na região de clima temperado. 1.ed. Pelotas: Embrapa Clima Temperado, 2000. 195p.

BOLETIM AGROCLIMATOLÓGICO Estação Agroclimatológica de Pelotas. Edição: EMBRAPA/UFPel, 1999.

BOLETIM AGROCLIMATOLÓGICO Estação Agroclimatológica de Pelotas. EMBRAPA/UFPel: 2000.

BRASIL. Controle da poluição. Ministério da Agricultura e do Abastecimento, Resolução do CONAMA N.20, de 18 de junho de 1986, 1995. 213p.

BRASIL. Instrução Normativa $\mathbf{n}^{0} 51$ de 18 de setembro de 2002. Ministério da Agricultura e do Abastecimento, Secretaria de Defesa Agropecuária, 2002.

R. Bras. Zootec., v.33, n.6, p.1531-1543, 2004
BRASIL. Métodos de análise microbiológica para alimentos. Ministério da Agricultura e do Abastecimento, Secretaria de Defesa Agropecuária, 1999. 489p.

BRUHN, J.C.; FRANKE, A.A. Monthly variations in gross composition of california herd milks. Journal of Dairy Science, v.60, p.696, 1977.

CARVALHO, M.P.; FONSECA, L.F.L.; PEREIRA, C.C. Manipulação nutricional da composição do leite: proteína e gordura. In: SIMPÓSIO INTERNACIONAL SOBRE PRODUÇÃO INTENSIVA DE LEITE, 4., 1999, Caxambú. Anais... São Paulo: Inst. Fernando Costa, 1999. p.19-35.

CUNHA, A.A.V.; COSTA, E.S.; MARTINS, J.L. et al. Manual de práticas de química analítica. Pelotas: Universidade Federal de Pelotas, 1984. 185p.

DÜRR, J.W.; WEISS, T.B.; MORO, D.V. et al. Monitoramento da qualidade do leite crú na região de Santa Rosa, RS. In: REUNIÃO ANUAL DA SOCIEDADE BRASILEIRA DE ZOOTECNIA, 36., 1999, Porto Alegre. Anais... São Paulo: Gnosis, 1999, 17par. CD-ROM. Qualidade de produtos de origem animal.QUA-025

FAGUNDES, C.M. Inibidores e controle da qualidade do leite. 1.ed. Pelotas: Universidade Federal de Pelotas, 1997. 126p.

FONSECA, L.F.L.; SANTOS, M.V. Propriedades e composição do leite. In: $2^{\circ}$ Curso online de atualização sobre controle de mastite. http://www.milkpoint.com.br./curso.mastite.asp, 2000.

FONSECA, L.F.L. Critérios no pagamento por qualidade. Revista Balde Branco, v.37, n.444, p.28-34, 2001.

FREDEEN, A.H. Consideration in nutricional modification of milk composition. Animal Feed Science Tecnology, v.59, p.185-197, 1996

GARCIA, S.C.; HOLMES, C.W. Lactation curves of autumnand spring- calved cows in pasture-based. Dairy Sistems Livestock Production Science, v.68, p.189-203, 2001.

GOERING, H.K.; Van SOEST, P.J. Forage fiber analysis (apparatus, reagents, procedures and some aplications). Agric. Res. Seervice. U.S. Dep. Agric. Washington, D.C., 1970.

GONZÁLEZ, F.H.D. Composição bioquímica do leite e hormônios da lactação. In: USO DO LEITE PARA MONITORAR A NUTRIÇÃO E O METABOLISMO DE VACAS LEITEIRAS, 1., 2001, Passo Fundo. Anais... Porto Alegre: 2001. p.5-21.

HARMON, R.J. Symposium: mastitis and genetic evaluation for somatic cell count. Journal of Dairy Science, v.77, n.7, p.2103-2111, 1994.

KITCHEN, B.J. Reviews of the progress of dairy science: Milk compositinal changes and related testes. Journal of Dairy Science, v.48, p.167-188, 1981.

LABEN, R.C. Factors responsible for variation in milk composition. Journal of Dairy Science, v.46, p.1293, 1963.

LACY HULBERT, S.J.; WOOLFORD, M.W.; NICHOLAS, G.D. et al. Effect of milking frequency and pasture intake on milk yield and composition of late lactation cows. Journal of Dairy Science, v.82, n.6, p.1232-1239, 1999.

MACKLE, T.R.; BRYANT, A.M.; PETCH, S.F. et al. Nutritional influences on the composition of milk from cows of different protein phenotypes in New Zealand. Journal of Dairy Science, v.82, p.172-180, 1999.

MATOS, R.S.; RORATO, P.R.N.; FERREIRA, G.B. Estudo do efeito de alguns fatores de meio sobre as produções de leite e gordura da raça Holandesa no Rio Grande do Sul. In: REUNIÃO ANUAL SOCIEDADE BRASILEIRA DE ZOOTECNIA, 33., 1996, Fortaleza. Anais... Fortaleza: Sociedade Brasileira de Zootecnia, 1996. 
MARKUS, M. Elementos da estatística aplicada. Porto Alegre: Universidade Federal do Rio Grande do Sul, Diretório Acadêmico Leopoldo Cortês. 1973. 329p.

MEPHAN, T.B. The development of ideas on the role of glucose in regulating milk secretion. Australian Journal of Agricultural Research, v.44, p.509-522, 1983.

NG-KWAI-HANG, K.F.; HAYES, J.F.; MOXLEY, J.E. et al. Environmental influences on protein content and composition of bovine milk. Journal of Dairy Science, v.65, p.19931998, 1982.

PIMPÃO, C.T.; RIBAS, N.P.; MONARDES, H. Estudo da produção de leite, gordura e percentagem de gordura em rebanhos Holandeses na Região de Arapoti, Paraná. In: REUNIÃO ANUAL SOCIEDADE BRASILEIRA DE ZOOTECNIA, 33., 1996, Fortaleza. Anais... Fortaleza: Sociedade Brasileira de Zootecnia, 1996.

RIBAS, N.P.; MONARDES, H.; MOLENTO, C.F.M. et al. Estudo dos efeitos do meio ambiente sobre características produtivas de vacas da raça Holandesa no Estado do Paraná. In: REUNIÃO ANUAL SOCIEDADE BRASILEIRA DE ZOOTECNIA, 33., 1996, Fortaleza. Anais... Fortaleza: Sociedade Brasileira de Zootecnia, 1996.

RIBEIRO, M.E.R.; GOMES, J.F.; STUMPF, W.J. et al. Manejo de ordenha e mastite. In: STUMPF, W.J.; BITTENCOURT, D.; GOMES, J.F. et al. (Eds.) Sistemas de pecuária de leite: uma visão na região de clima temperado. 1.ed. Pelotas: Embrapa Clima Temperado, 2000.195p.

RODAS, A.C.; ISEPON, J.S.; ALVES, J.B. et al. Efeito da sazonalidade na qualidade do leite "in natura" em Pereira Barreto (SP). In: REUNIÃO ANUAL DA SOCIEDADE BRASILEIRA DE ZOOTECNIA, 36., 1999, Porto Alegre. Anais... Porto Alegre: Sociedade Brasileira de Zootecnia, 1999. CD ROM

ROSENFELD, A.M.F.; DELLA LIBERA, A.M.M.P.; GARCIA, M. et al. Influência do número de lactações e fase da lactação na contagem de células somáticas de amostras de leite de vacas não infectadas. In: CONGRESSO BRASILEIRO DE MEDICINA VETERINÁRIA, 2000, Águas de Lindóia. Anais... Águas de Lindóia: CONBRAVET, 2000. p.19.
SANTOS, M.V. Contagem de células somáticas e qualidade do leite e derivados. In: SIMPÓSIO INTERNACIONAL SOBRE PRODUÇÃO INTENSIVA DE LEITE, 5., 2001, Belo Horizonte. Anais... Belo Horizonte: Instituto Fernando Costa, 2001. p.115-127.

STATISTICAL ANALYSES SYSTEM - SAS. User's guide. version 6, 4.ed. Cary: 1989.

SCHALM, O.W.; NOORLANDER, D.O. Experimental and observation lading to development of California Mastitis Test. Journal of American Veterinery Medicine, v.130, p.199-204, 1957.

SHUSTER, D.E.; HARMON, R.J.; JACKSON, J.A. et al. Suppression of milk production during endotoxin-induced mastitis. Journal of Dairy Science, v.74, p.3763-3774, 1991.

SILVA, P.H.F.; PEREIRA, D.B.C.; OLIVEIRA, L.L. et al. Físico-química do leite e derivados - métodos analíticos. Juiz de Fora: Oficina de Impressão Gráfica e Editora Ltda, 1997. 190p.

STUMPF, W.J.; BITTENCOURT, D.; GOMES, J.F. et al. Sistema de produção In: STUMPF, W.J.; BITTENCOURT, D.; GOMES, J.F. et al. (Eds.) Sistemas de pecuária de leite: uma visão na região de clima temperado. 1.ed. Pelotas: Embrapa Clima Temperado, 2000. 195p.

TRONCO, V.M. Manual para inspeção da qualidade do leite. 1. ed. Santa Maria: Universidade Federal de Santa Maria, 1997. 166p. 